\title{
Lecture two: The evolution of morality: The emergence of personhood
}

Author:
J. Wentzel van Huyssteen ${ }^{1,2}$
Affiliations:
1Princeton Theological
Seminary, United States
2Faculty of Theology,
Stellenbosch University,
South Africa
Corresponding author:
J. Wentzel van Huyssteen,
wentzel.vanhuyssteen@
ptsem.edu
Dates:
Received: 09 Dec. 2016
Accepted: 21 Aug. 2017
Published: 30 Nov. 2017
code with your
How to cite this article:
to read online.
Van Huyssteen, J.W., 2017,
'Lecture two: The evolution
of morality: The emergence
of personhood', HTS
Teologiese Studies/
Theological Studies $73(3)$,
a4487. https://doi.org/
10.4102/hts.v73i3.4487
Copyright:
C 2017. The Authors.
Licensee: AOSIS. This work
is licensed under the
Creative Commons
Attribution License.

In a series of three articles, presented at the Goshen Annual Conference on Science and Religion in 2015, with the theme 'Interdisciplinary Theology and the Archeology of Personhood', J. Wentzel van Huyssteen considers the problem of human evolution - also referred to as 'the archaeology of personhood' - and its broader impact on theological anthropology. This trajectory of lectures tracks a select number of challenging contemporary proposals for the evolution of crucially important aspects of human personhood. Lecture Two argues that, on a postfoundationalist view, some of our religious beliefs are indeed more plausible and credible than others. This also goes for our tendency to moralise and for the strong moral convictions, we often hold. It demonstrates that, in spite of a powerful focus on the evolutionary origins of moral awareness, ethics emerge on a culturally autonomous level, which means that the epistemic standing of the particular moral judgements human beings make is independent of whatever the natural sciences can says about their genesis.

\section{Introduction}

As we saw in the first lecture, it is the materiality of our embodied existence that has come about through the long process of biological evolution and has given us what seems to be a unique human sense of self. Cognitive archaeologist Steven Mithen puts it well: one's self-identity is intimately related to the feeling that one has a suite of beliefs, moods, desires and feelings that are quite unique to oneself (cf. Mithen 2009:214). Some of French philosopher Paul Ricoeur's last work before his untimely death in 2005 not only provides us with a remarkable in-depth analysis of exactly this notion of self, but at the same time provides us with a philosophical bridge theory from evolutionary anthropology to interdisciplinary theology, and finally, to incentives for rethinking theological notions of human distinctiveness.

Ricoeur has developed, as is well known, a striking notion of the human self as defined, at the deepest level, by the depth of its historical dimension, that is, by time and narrative. For Ricoeur, the narrative dimension of human self-awareness and consciousness not only enables us to envision new projects, to evaluate motivations, to initiate viable courses of action, but the narrative also enables us to deeply empathise and identify with others. Ricoeur claims that a narrative understanding provides us with an ethics of responsibility which then propels us, precisely through empathy, beyond excessive self-reference to relationships with others (cf. Ricoeur 1992:113-139). It is this extension of the 'circle of selfhood' that involves an enlarged mentality ultimately capable of imagining the self in the place of the other. In this way, Ricoeur has revisioned the notion of narrative understanding - where one represents oneself as another - to the extent that it ultimately liberates us from all-consuming narcissistic interest without liquidating our fragile identity as selves. Narrative understanding thus generates a basic act of empathy whereby the self flows from itself towards the other in a free variation of imagination. Thus, narrative imagination transforms self-regarding into a self-for-another. In his acclaimed Gifford lectures, Oneself as Another, Paul Ricoeur could then argue that our sense of self, our personal identity, should be understood precisely in terms of this narrative identity. Through the power of imagination, the self is able to weave together various elements of a life into a single story, just as we also maintain a sense of personal identity when we stay true to our promises over time.

In the philosophical framework that Ricoeur builds, then, memory serves as the ultimate mediator between time and narrative, while imagination leads the way in forging an understanding of the human self as oneself only in and through the other person. As such, personal identity, or 'self', is both articulated and constructed solely through the quintessential human niche provided by the temporal and relational dimensions of embodied human existence. On this view, self-identity rises out of our narrative identities, and in many narratives, the self as a lived body seeks its 
identity for the duration of an entire lifetime (cf. Ricoeur 1992:115). In this way, Ricoeur could even anticipate contemporary multiple selves' theories and could explicitly state, 'to be a human being is to live at the same time at several levels of self-structuring, of the constitution of selfidentity' (cf. Ricoeur \& Homans 2008).

It is in this way, then, that the defining role of narrative understanding in Ricoeur's work clearly points to the important role of interpretation and explanation as it participates in the construction of the hermeneutical self. Interpretation for Ricoeur can be said to engage us in a hermeneutical circle of historical intersubjectivity, precluding any idealist claim to occupy an absolutist, totalising standpoint as a rational self. On the contrary, to interpret meaning, for Ricoeur, is to arrive in the middle of an exchange that has already begun and in which we seek to orient ourselves in order to make sense of it. It is in this sense, then, that for Ricoeur, the 'self-as-another' is attained only after our complex interpretative detours of experience. Hermeneutical selfhood is not that which initiates understanding, but that which terminates it: it exists at the end, not at the beginning, and in this sense, the retrieval of selfhood lies at the far end of the hermeneutical circle (cf. Kearney, R., op. cit., p. $5 \mathrm{ff}$.). It is exactly in this sense that the shortest route to the self is through the other: the self only returns to itself after numerous hermeneutical detours through the embodied language of others, to find itself enlarged and enriched by the journey. Finally, it is the bodily embeddedness of the self in time through memory and imagination, which also reveals an ethical link of the sense of self to the future: insofar as my personal identity is dependent on me keeping my word, the act of promising binds me to the future.

Although he rarely refers to Paul Ricoeur, British cultural philosopher Roger Scruton, in his recent book The Face of God, (2012), based on his 2010 Gifford Lectures, takes up these crucial themes and eventually, and also surprisingly, pushes Ricoeurian ideas of 'self' now to include the central idea of the 'religious self', and ultimately God. Like Martin Buber's famous $I$ and Thou, Scruton starts from the observation that being present to another as a person is radically different from being in the vicinity of a mere objective thing. The former, like in Ricoeur, is radically intersubjective, for when one person acknowledges another as a person, this immediately implies a whole range of reciprocal, morally charged relations. Thus, the first-person perspective both empowers and restricts the one who is capable of expressing it, opening up to the prospect of love but also subjecting one to the authority of obligation. On this view, the human spheres of family, neighbourhood and church are the outgrowths of our capacity for first person relations and our typical patterns of behaviour, affect and judgement, and are distinctive and precarious achievements that distinguish human persons from 'mere' animal existence.

Scruton also argues that it is not the facile 'new-atheist' arguments of the Dawkinses and Dennetts that threaten to dissolve religious faith, but rather a culture that relentlessly treats persons as if they were mere things, and reduces human aspirations to brute desires. In such a culture, God is denied because the face of the human person has already been blotted out. For Scruton, however, the question 'what does it means to be a person in a world of objects?' is a necessary preliminary to the question 'what and where is God?' Strikingly, for Scruton, this question actually answers the question whether God is a person or not: if we are indeed, as Genesis teaches, created in the image of God, then human nature and human community are instances of God's presence in the world. In this way, the personhood that is exhibited in the human face gets extended to finally reflect the 'face of God'. In so doing, Scruton, I would say, creates the possibility for a bottom-up theological anthropology that wants to show that God's presence in the world is discoverable only if we attend to the nature and significance of human community. It is there that the face of God, in the person of Jesus Christ, has been made present to us (cf. Scruton 2012:172).

This ultimately is Scruton's answer to materialism and scientism: in a truly interdisciplinary world, the qualities of human personhood, and of God as a person, cannot be explored as mere objects. This also makes clear what God is not: God is not mysterious and supernatural, but is present to us through Jesus Christ in the faces of others. Scruton (2012) also explicitly rejects all dualism in understanding the self and its body, and in this way, he also wants to observe the mystery of human consciousness and save it from those who would reduce it to biology and neuroscience. .

This has profound implications for the question of God's presence in the world. If one looks at the world only with the objectifying eyes of science, it is impossible to find the place, time or the particular sequence of events that can be interpreted as showing God's presence. God disappears from the world as soon as we address it with the 'why?' of explanation, just as the human person disappears from the world when we look only for a neurological explanation of his or her acts (cf. Scruton 2012:45). So maybe, after all, God is a person like us, whose identity and will are bound up precisely with God's nature as a subject. Maybe we shall find God in the world where we are only if we cease to invoke God with the 'why?' of causality, and address God with the 'why?' of reason, and the 'why?' of understanding instead. And for Scruton, the 'why?' of reason and understanding must be addressed from 'I' to 'you' (cf. Scruton 2012:45).

In a striking paragraph, Scruton (2012) concludes this line of thinking by stating:

You can situate human beings entirely in the world of objects. In doing so you will in all probability reduce them to animals whose behaviour is to be explained by some combination of evolutionary psychology and neuroscience. But then you will find yourself describing a world from which human action, intention, responsibility, freedom and emotion has been wiped away: it will be a world without a face. The face shines in the world of objects with a light that is not of this world - a light of subjectivity. You can look for freedom in the world of objects and you will not find it: not because it is not there, but because it is bound up with the first person perspective, and with the view from somewhere of the creature who can say ' $\mathrm{I}$ '. (cf. p.49) 
In this argument, Scruton is not at all just making a simplistic distinction between 'interpretation' and 'explanation', but is actually opening up a door to the stunning complexity of talking about the human person and the person of God in a radically interdisciplinary way. For this reason, Scruton can distinguish between the 'why?' of science (that looks for causes), the 'why?' of reason (that looks for arguments) and finally the 'why?' of understanding (that looks for meanings, meanings that may be inaccessible to causal thinking and rational argumentation; cf. Scruton 2012:68). I believe that these various levels of thinking might all have their place in theology and in theological anthropology, but the comprehensive 'why?' of understanding clears the way for incorporating a powerful role for aesthetics in coming to grips theologically with uniquely human experiences such as suffering, tragedy, guilt and redemption. For Scruton, this happens especially and sacramentally through the Christian Eucharist, and it is one reason why the meaning of the sacrament is so easy to experience, but so hard to explain unless we explain it through a work of art, as the German composer Richard Wagner so stunningly achieved in his drama Parsifal (cf. Scruton 2012:20). In Scruton's quest then for understanding the religious self, aesthetics is now brought alongside theology and the sciences with a unique task to probe what cannot be probed by the natural, human, or social sciences.

\section{From empathy to moral awareness: A natural history of morality?}

I believe that Paul Ricoeur's profound vision of deep empathy for others also opens up a way to bridge the gap between evolutionary and theological meta-narratives by making a proposal for a bottom-up, contextual form of evolutionary ethics and then specifically to ask how this might apply to the evolution of morality, to ethical judgements, and the status of ethical judgements and moral codes in theology. Most importantly, this will imply a Christian ethics, and a notion of morality that proceed not 'top down' from a consideration of rules, duties, rights, moral judgements and moral status, but proceeds rather, from the examination of the fundamental evolutionary realities of human nature, that is, from a natural history of morality. I will develop this argument against the background of an analysis of Maxine Sheets-Johnstone's engagement with the work of Hannah Arendt on the notion of evil, and in conversation with Richard Joyce as well as the most recent work on the origins of morality by anthropologist, Christopher Boehm. Finally, I argue that the work of evolutionary ethicists is of great importance for theologians because of their direct interest in how the evolutionary origins of human behaviour are to be explained, and in which way our behaviour has been constrained, but not determined, by biological factors. Following from our discussion of niche construction in Lecture One, it will be clear that evolution by natural selection and genetics can play an important role in our tendency to think in normative terms, that is, our innate sense of moral awareness. However, evolutionary explanations of this moral awareness cannot explain our moral judgements, nor justify the truth claims of any of our moral judgements. Why and how we make moral judgements can only be explained on the more complex level of niche construction and cultural evolution, and by taking into account the historical embeddedness of our moral codes in religious and political conventions. For Christian theology, in the end, the choice will not be between a moral vision that is inherent in revelation and is therefore 'received' and not invented or constructed. Instead, on a postfoundationalist view, our moral codes and ethical convictions of what is 'received' is itself an interpretative enterprise shaped experientially through our embeddedness in complex niches of communities and cultures. Against this background, I want to try in this essay to begin to bridge the gap between evolutionary and theological meta-narratives by making a postfoundationalist proposal (cf. van Huyssteen 2006:6-24) for a bottom-up, contextual form of evolutionary ethics, and then specifically ask how this might apply to the evolution of morality, to ethical judgements, and the status of ethical judgements and moral codes in theology.

In her fascinating studies, especially her acclaimed Roots series, Maxine Sheets-Johnstone goes to the evolutionary roots of human cognition, language and communication by developing a very pronounced 'hermeneutics of the human body' (1990; 1994; 2008). Throughout all her work, the emphasis is on the role of the human body in understanding meaning and mind. The most fundamental theme advocated in her work, however, is the existence of a biological disposition to use one's own body as a semantic template for the way we communicate with others. Sheets-Johnstone wants to go even further, however, and 'get back' to our hominid roots through the evolutionary continuum of the tactile-kinaesthetic body (cf. 1990:280), so as to illuminate the evolution of sexuality, language, cognition and morality. Ultimately, Sheets-Johnstone argues that the biological disposition to use one's own body as a semantic template to communicate with others in the most fundamental sense of the word is about symbolic behaviour and conceptual origins (1990:3), or what Steven Mithen would call the emergence of cognitive fluidity in the embodied human mind (cf. Mithen 1996:70, 136). Her fascinating thesis is that human thinking is modelled on the body, and it is precisely the sensorily felt and sensorily feeling body that serves as the cognitive source of those human concepts that continuously shaped human thinking and evolution, thus functioning as a semantic template $(1990: 5,6)$. It is against this background that SheetsJohnstone argues that many contemporary answers to the origins of language fall short as they continue to ignore the reality that 'no language can be spoken for which the body is unprepared' (1990:135). For me, the logical conclusion from this will be that also many answers to the origins of the moral sense and the religious disposition will fall short of we ignore the reality that no moral or religious convictions can be articulated for which the human body is unprepared.

No wonder, then, as the path from embodiment leads directly to the evolution of empathy and the moral sense, the fundamental embodied roots of morality have been of utmost 
importance in Maxine Sheets-Johnstone's most recent work. For Sheets-Johnstone, empathy goes to the evolutionary heart of human personhood. Our ability to care, to trust, to empathise and have deep feelings for others is essential to the development of moral awareness and the realisation of a fully resonant human being (cf. Sheets-Johnstone 2008:193f.). As such it gives us access to the mental acts and processes of others, and through empathy, we discover the feelings and values of others, what their convictions are, and precisely through this capacity for empathy, we ultimately share what Husserl already described as an intersubjective world, that is, a communally intelligible world (cf. Sheets-Johnstone 2008:194). And of crucial importance, although often neglected, in empathy, we basically make sense of each other in ways outside of language.

Maxine Sheets-Johnstone's work on the roots of morality is infused by the fact that in hominid and human history, there clearly emerged a deeply embodied sense of empathy: and the core phenomenon we observe when we reflect on our own empathetic actions is not simply a body, but a moving body. Movement is an unfolding dynamic event and we, in fact, have perceptions of movement as well as feelings of movement. Sheets-Johnstone accurately describes this as a double spatial sense of movement: we perceive our movement as a kinetic three-dimensional happening; and we feel the qualitative dynamics of our movement kinaesthetically (cf. SheetsJohnstone 2008:199). It is in this sense that empathy is through and through indicated somatically: it is indeed not merely a question of a body, but of a body in movement. Indeed, in empathy, we move in ways we are moved to move (cf. SheetsJohnstone 2008:207f.). It is in this sense that empathy is through and through indicated somatically: it is indeed not merely a question of a body, but of a body in movement.

Maxine Sheets-Johnstone also follows infant psychiatrist Daniel Stern (1985) and makes an important conceptual distinction between attunement and empathy: in this way, an important distinction is made between neurological motherinfant attunement and attachment, and embodied empathetic movements or understandings that flow from this. What is thus revealed is that our cognitive understandings finally enter deeply into the congruent dynamics of both attunement and empathy. Furthermore, both attunement and empathy start with an emotional resonance, but attunement takes the experience of emotional resonance and automatically recasts that experience into another form of expression. So, for Sheets-Johnstone, attunement occurs largely beyond awareness and almost automatically, while empathy involves the mediation of cognitive processes (cf. SheetsJohnstone 2008:203).

For Sheets-Johnstone, empathy is, furthermore, an embodied form of responsivity. It is never just a form of mental construction, and it is never just a one-sided experience, but it is rather a spontaneous embodied response to direct experiences of the other, and from its foundations in affect attunement and attachment, it progressively discloses richer and more complex dimensions of others. In exactly this sense, empathy is seeing deeply into another, and, I would add, in a more Ricoeurian way, finding oneself in another, finding oneself as another (cf. Ricoeur 1992:1-29). Responding empathetically then, we experience the density of another person, the meanings that are livingly present for him or her (cf. Sheets-Johnstone 2008:225f.). And importantly, these deepened understandings of another over time are not readymade but mature progressively as we ourselves mature. We grasp at ever deeper levels what another is living through because we have ourselves grown in life experiences and thus reach out to the deepest levels of one another, as we together become more mature, intricate and trustworthy persons in the process.

Against the background of this illuminating discussion of empathy, Sheets-Johnstone now adds the notion of trust. Trust, as deeply embedded in empathy, is already grounded in a non-linguistic sense of the other that is rooted in sensitive and deep awareness of the feelings, dispositions and intentions of the other towards us (cf. Sheets-Johnstone 2008:265). And it is only the learning of trust that can ultimately overcome the existential meaning and impact of uncertainty. But because its cognitive structure is always open to affective influence or some form of fear, the cognitive structure of trust can be unstable. Only if and when we arrive at a fuller understanding of our relationship with the other and of the affective foundations of trust will we be able to arrive at a fuller understanding, and an overcoming of, the more fragile nature of the cognitive structure of trust (cf. SheetsJohnstone 2008:281). And it is this ever maturing cognitive structure of trust, so deeply embedded in the embodied, affective structure of empathy, which ultimately opens the door to a mutual rationality of care for one another.

In further developing this argument, Sheets-Johnstone now calls for philosophical and evolutionary ways to understand how empathy is indeed a spontaneous outgrowth of affect attunement and emotional attachment (cf. Sheets-Johnstone 2008:211; cf. also Kirkpatrick 2005). Empathy also has direct links to Theory of Mind, that is, our intuitive knowing of the minds of others. For Sheets-Johnstone, this is now enriched by redefining Theory of Mind as getting to know not just other minds, but getting to know other moving bodies (cf. Sheets-Johnstone 2008:213ff.). In principle, Sheets-Johnstone thus offers us a fascinating evolutionary trajectory for engaging any project in ethics that opens up an understanding for a particular form of interanimate meaning, namely empathy, moral awareness and a rationality of care (cf. SheetsJohnstone 2008:215). It is this rich revisioning of a profoundly embodied notion of empathy, I believe, that will eventually become a crucial building block for understanding the evolution of morality, of notions of good and evil, and although Sheets-Johnstone herself does not go there, to a responsible way of thinking about the evolution of religion (cf. van Huyssteen ; 2011a; 2011b).

Thus, in trying to understand the evolutionary roots of human morality through affective attunement and empathy, Maxine 
Sheets-Johnstone develops what I would call a 'bottom up' understanding of morality grounded in the nature of human nature. Most importantly, for her, this evolutionary approach to the understanding of the roots of morality directly implies a phenomenological exploration of human experience, including the phylogenetic and ontogenetic heritages of humans, experiences of the embodied human psyche and of the very basic facets of embodied human existence (cf. SheetsJohnstone 2008:1f.). Most importantly, this implies a morality that proceeds not from a consideration of rules, duties, rights, moral judgements, moral status or leading current ethical issues in Western society or the world at large, but proceeds rather, and first of all, from the examination of the fundamental evolutionary realities of human nature. As such she articulates multidisciplinary and multilayered understandings of human morality that are ultimately grounded, as we will see, in a natural history of morality.

For Sheets-Johnstone, the need for such an 'interdisciplinary therapeutic' is called for because an ethics based on anything other than human nature would lack solid empirical moorings and easily loses itself in the reductionist abstractions of disembodied, abstract issues such as selfish genes, dedicated brain modules reductionist views of evolutionary altruism and so on (cf. Sheets-Johnstone 2008:2). Following the historical line of Hume, Rousseau, and Hobbes, whom she sees as developing, each in his own way, an understanding of morality rooted in what he saw as the nature of human nature (cf. Sheets-Johnstone 2008:2ff.), Sheets-Johnstone reclaims a strong empirical approach that is based on evidence from both personal and social experience. Not only that, but Sheets-Johnstone casts her evolutionary approach in a phenomenological perspective so that it could be seen as offering a profile of human nature, that is, just as an object offers multiple possible profiles to a phenomenological observer, so also does human nature (cf. Sheets-Johnstone 2008:2). For her, the challenge, in effect, is to discover the nature of the human condition on the basis of the kinds of profiles that emerge when we carefully observe human nature, and so to take the first steps to reveal the roots of human morality. ${ }^{1}$

Building now on the deeply embodied sense of empathy as discussed earlier, the biological roots of empathy can fundamentally be seen as enabling a social transfer of sense through embodied communication. As such, from an evolutionary perspective, empathy translates naturally into a basic moral sense, that is, how it is first and foremost generated from, and anchored in social and affective bodily experiences, and how it is ultimately sustained by trust in interpersonal relationships (cf. Sheets-Johnstone 2008:7).

Ultimately, of course, Sheets-Johnstone argues that the pancultural origins of both empathy and evil clearly have their roots in the evolutionary heritage of humans, though just as

\footnotetext{
1.Throughout the book, her approach then unfolds in three successive steps: (1) what we have learned from others, (2) broadening that knowledge by putting it in preliminary evolutionary and ontogenetically perspectives and (3) deepening this preliminary evolutionary and ontogenetically perspectives and (3) deepening this
phenomenologically by probing along elusive experiential borders to reach the phenomenologically by probing along elusive experie
roots of human morality (cf. Sheets-Johnstone 2008:6).
}

clearly those roots stretch all the way from the biological to the cultural. The whole point, then, of Sheets-Johnstone argument for the pan-cultural origins of evil is to show that violence and war are socially elaborated, biological derived phenomena. And to best unravel the pan-cultural origins of evil through a local, bottom-up, contextual, phenomenologically informed attention to war and violence, Sheets-Johnstone now turns to Hannah Arendt's most famous writings on war and evil. Here, what Arendt has called the 'banality of evil' is indeed pancultural, not only in the immediate sense of being a presentday world-wide human phenomenon, but in the enduring sense of being a chronic historically laden human phenomenon (cf. Sheets-Johnstone 2008:137). This certainly directly implies the natural history that undergirds the banality of evil, a history that, cultural variations notwithstanding, has phylogenetic and thus evolutionary roots.

And it is here that we find Maxine Sheets-Johnstone's particular evolutionary deepening and enriching of Hannah Arendt's argument: to trace the roots of the natural history that underlies the banality of evil requires an elucidation of the nature of human nature in evolutionary terms that does justice both to the essential realities and intricate complexities of the human capacity for evil (cf. Sheets-Johnstone 2008:137). Sheets-Johnstone therefore argues powerfully that an inquiry into the origin of the pan-cultural human capacity for evil is in essence an attempt to flesh out, in phenomenological terms, an answer not just to the question what is evil?, but rather to the question, what motivates evil? In this way, SheetsJohnstone could broaden Arendt's 'keenly accurate concept of the banality of evil' by showing what a universal dimension and consistently present element evil has been in the history of humanity (cf. Sheets-Johnstone 2008:138f.).

For Sheets-Johnstone, this starts with a consideration of behavioural evolutionary relationships, and by probing our animal heritage for clues to the pan-culturality of evil. In doing so, not only important evolutionary roots are exposed, but also the remarkable cultural elaborations of those through the course of history. Rooted in human evolutionary history, the pan-culturality of evil is precisely culturally elaborated, induced and perpetrated along a diversity of lines (cf. SheetsJohnstone 2008:140). Following a discussion of what SheetsJohnstone calls the 'pan-cultural heroic honing of males' for aggression and violence, and its direct relation to the banality for evil, Sheets-Johnstone now nuances her discussion by explaining as follows: in trying to discern the exact relationship between empathy (or rather the lack of empathy) to evil, it is important to realise that by itself a lack of empathy is not yet a motivation of evil, just as a lack of judgement is not yet a motivation for evil. Neither the lack of empathy nor the lack of judgement could explain the outright deliberate motivation to harm or kill others, and this is because the human capacity for evil is just that, a capacity (cf. SheetsJohnstone 2008:156). This, indeed, is not yet the banality of evil itself but only its potential. The capacity is thus not ready-made, and an ability to act on it may or may not be realised; hence, a capacity is a potential that can be tapped 
into, drawn on, encouraged, nourished, culturally elaborated and promoted. So cultivated, the capacity produces humans who are exemplars of the banality of evil. From an evolutionary point of view, then we humans are born with a moral sense for right and wrong, a capacity for good and evil. As such humans are not born evil, but have, in addition to a capacity for empathy, the capacity to harm and kill other humans, a capacity that can be culturally fostered and valued to the point of taking over whole societies. Morality is thus indeed, and first of all, an individual matter, but its roots lie deep in our human evolutionary history (cf. Sheets-Johnstone 2008:18, 157).

Thus, it becomes clear why, in completing this argument, SheetsJohnstone has called for philosophical and evolutionary ways to understand how empathy is indeed a spontaneous outgrowth of affect attunement (cf. Sheets-Johnstone 2008:211), and also why she wants to build on her research on empathy to develop a 'rationality of caring' that, in turn, offers deepened understandings of empathy. As has now become clear, she also wants to ground her phenomenological approach by consciously embedding it in Charles Darwin's natural history of the moral sense. In doing so, she is making a bold attempt at revealing the inherent link between ethics and biology, thereby laying the ground for a genuine evolutionary ethics (cf. Sheets-Johnstone 2008:286). In this way, a rationality of caring grows out of the insight that one's own body is the standard upon which the plight, concerns, thoughts and feelings of another are grasped. One's own body is indeed a semantic template for those intercorporeal understandings that ground the rationality of caring, and, in fact, generate caring as an attitudinal affect (cf. Sheets-Johnstone 2008:287). In this 'transfer of sense', an understanding of another's movements, gestures, words, cries, postures and expressions (i.e. another's behaviour in the widest possible sense) is engendered and the capacity for empathy is revealed, a capacity to enter in a dynamically and affectively intuitive sense into the life of another. A genuine evolutionary ethics thus makes explicit the epistemological structures of empathy and caring, while at the same time, it anchors those structures in the corporeal facts of evolutionary life (cf. Sheets-Johnstone 2008:288), and thus enables a leading of the moral life. Or, as Sheets-Johnston strikingly puts it: before being able to give reasons for one's actions and beliefs - the common criteria of rationality - one should be able to act reasonably in the world and have reasonable beliefs about it (cf. Sheets-Johnstone 2008:302).

The work of evolutionary ethicists is therefore of great importance for theologians because of their direct interest in why humans behave the way they do, how the evolutionary origins of human behaviour are to be explained, and in which way our behaviour has been constrained by biological factors. In this sense, one could say that the starting point of evolutionary ethics is the insight that morality has a biological, evolutionary basis. Ethical behaviour is indeed a product of our biological evolution but this fact by itself does not entail any normative assertions: from the fact that morality has developed, we cannot conclude that any particular trait of human behaviour is good or bad (right or wrong) in an ethical sense. Put differently, an evolutionary account of ethics does not support any particular moral code, but it may help us understand why such codes have developed (cf. Wuketits 1990:202). We should therefore be careful to always distinguish between the evolution of moral awareness and any attempt at the evolutionary justification of moral codes. Evolutionary ethics in this second sense has a bad history and has resulted in ideologies like Social Darwinism.

When I use the term evolutionary ethics, I use it to characterise specifically the view that morality has evolved and there are clear pointers to the biological roots of moral behaviour in pre-human history, as the work of primatologist Frans De Waal (2006), scientist Donald Broom (2003) and philosopher Richard Joyce (2006) have clearly shown. However, from the evolutionary genesis of our moral awareness, we cannot derive moral codes for right or wrong. Accepting that our moral awareness has evolved also means accepting that our moral codes may not be fixed forever as unchangeable entities.

As humans, therefore, we are indeed free to find our own moral goals in this world, and an evolutionary approach to ethics and morality helps us understand under which circumstances we have created the kinds of values and moral codes that we have. Certainly, some traits of our moral behaviour may be derived from archaic behavioural patterns and from the intense drive to survive. If moral codes have regulated the interactions among individuals in a society, then these codes must also have been useful for survival. In fact, to our phylogenetic ancestors, there must have been some survival value to believe that moral codes are simply given, and therefore authoritative and objective - as is still found today in the belief that ethical norms are unchangeable and derivable from some set of eternal, divine principles. In an evolutionary approach to ethics, the status of these kinds of beliefs will rightly be challenged, and the creation of moral norms, in an a posteriori sense (to use Kantian terms), will be found to lie on a constructive, cultural level. This, of course, means that humans in principle are free to change their moral codes, but this also means that humans carry great responsibility for themselves and that this responsibility cannot and should not be easily delegated to 'objective divine moral codes' (in this sense, e.g. even the Ten Commandments and Jesus' love command, over time, are historically revealed as a posteriori moral laws, even as they have acquired over time the authority of biblical truth). This also frees us from the foundationalist need for an idea of absolute moral truth: our idea of truth is relative to our historical and social contexts and their histories, and only a coherentist, postfoundationalist approach can sufficiently explain this. What we find here, then, is an open view of evolution: basic patterns of our behaviour depend on, and have been developed through, our evolutionary past. But this is not a deterministic view, because we humans have the 
responsibility to make our own decisions on what counts as the norms and limits to our own behaviour. We are therefore constrained, but not determined by our evolutionary past.

\section{From empathy to moral awareness}

The work of Maxine Sheets-Johnstone has recently found, in my view, strong affirmation in anthropologist Christopher Boehm's latest publication, Moral Origins: The Evolution of Virtue, Altruism, and Shame (2012). Boehm, in a strong affirmation of Agustin Fuentes and other evolutionary anthropologists' notion of niche construction, argues that human behaviour is not determined either by biology, or by nature, but by interactions between these two factors. Boehm also recognises that culturally instilled beliefs and attitudes support evolved dispositions, that brain mechanisms affect the evolution of culture and that cultural innovations affect biological evolution (cf. Boehm 2012:3-4; Krebs \& Denton 2013:16). Boehm puts it as follows: 'In modern terms, what Darwin's theory told the world was that potentially changeable natural environments were acting continuously on variations of gene pools of resident populations'. In this way Boehm starts the challenging task of offering us a natural history of morality, something that Darwin himself could not fully accomplish: not because of any lack if insight or ambition, but because in his time, he lacked the necessary data from primatology, palaeoanthropology, cultural anthropology and psychology, along with explanations of brain functions from cognitive neuroscience (cf. Boehm 2012:13).

Like Sheets-Johnstone, Boehm steps back into prehistory to look for the roots of morality. First, Boehm assumes that members of archaic groups would have suppressed their selfish and dominant behaviours based on fear, in much the same way that dogs, wolves and chimpanzees do. However, given the premium of egalitarian behaviour in hunter and gatherer groups, and the strong tendency of members of these groups to punish cheaters and bullies, individuals who inherited the ability to internalise rules and exert self-control would have fared better biologically and genetically than those who did not, and as such then mediating the evolution of conscience. In addition, Boehm suggests that other evolutionary processes, such as group selection, sexual selection and indirect reciprocity, would have been given a boost by the forms of social selection he emphasises because individuals - and groups - who shared food an punished bullies and cheaters would have fared better than individuals - and groups - who did not (cf. Krebs \& Denton 2013:16). Boehm's historical journey finally ends with modern humans, and he asserts that biologically based moral evolution ended some 45000 years ago with the advent of the first fully modern humans (cf. Boehm 2012:17f.).

Boehm's basic thesis then is that prehistorically humans began to make use of social control so intensively that individuals who were better at inhibiting their own antisocial tendencies, either through fear of punishment or through absorbing and identifying with their group's rules, gained superior fitness. And by learning to internalise rules, humankind acquired a conscience (cf. Boehm 2012:17). In this sense, the long 'road to morality' ends with the first fully 'modern' humans, and they were basically the end point for moral evolution in the biological sense. In this sense, one could say that the uniquely self-conscious agency of the human person went hand in hand with the evolutionary development of the uniquely human conscience, and thus, as we saw earlier in the work of Maxine Sheet-Johnstone, with an inherent moral sense for right and wrong (cf. Boehm 2012:17). What is more, it is also exactly the development of conscience, which gave us the first primitive sense of right and wrong, which quickly re-enforced the remarkable degree of empathy, and finally the accompanying traits of extrafamilial generosity and altruism, which enrich our human lives today (cf. Boehm 2012:18). Boehm would also acknowledge recent work establishing the existence of empathy, undoubtedly a precursor of morality, in primates. But it is our evolutionary developed conscience, which has endowed us with a universal sense of shame, manifested in the unique human ability of blushing as an expression of shame, which was pivotal in the origin of morality (cf. Boehm 2012:14ff.).

Primatologists like Frans De Waal have long argued that the roots of human morality can be clearly discerned in social animals like apes and monkeys. In fact, these animals' feelings of empathy and their expectations of reciprocity are essential behaviours for mammalian group living and, from an evolutionary viewpoint, can be regarded as the building blocks of human morality. At the background of this argument, it is the fact that all social animals have had to constrain or alter their behaviour in various ways for group living to be worthwhile. Exactly these constraints, evident in monkeys and even more so in chimpanzees, are part of the human inheritance too, and in De Waal's view form the set of behaviour from which human morality has been shaped (cf. Wade 2007:1). Importantly, de Waal is not asking us to think about animals as moral beings and he does not claim that even chimpanzees possess morality. But he does argue that human morality would be impossible without certain proto-moral emotional building blocks that are clearly at work in chimpanzee and monkey societies.

For his notion of proto-morality, De Waal points especially to the presence of consolation and empathy in primates and humans. Social living requires empathy, which is especially evident in chimpanzees, as well as ways of bringing hostilities to an end. De Waal has found that every species if monkey has its own protocol for reconciliation after fights and believes that these actions are undertaken for the greater good of the community and as such are a significant precursor of morality in human societies. In addition, primates also have a sense of reciprocity and fairness. For De Waal, then, four kinds of behaviour could be seen as the basis of sociality: (1) empathy, (2) the ability to learn and follow social rules, (3) reciprocity and (4) peacemaking. Human morality in this sense has grown out of primate sociality, but with two extra levels of sophistication: humans enforce their society's moral codes much more rigorously with rewards, punishment and reputation building, exactly what we have seen in Christopher 
Boehm's most recent work. They also apply a degree of judgement and reason for which there are no parallels in animals (cf. also Wade 2007:2f.). In Peter Singer's words: though a capacity for reason helps us to survive and reproduce, once we develop a capacity for reasoning, we may be led by it to places that are not of any direct advantage to us in evolutionary terms. In this sense, human reason is like an escalator - once we step on it, we cannot get off until we have gone where it takes us (Singer 2006:146).

In his argument that our human morality grows out of the social instincts, we share with bonobos, chimpanzees and apes, De Waal also criticises what he calls the 'veneer theory', which holds that human ethics is simply an overlay of our selfish and brutish nature. De Waal draws on his own extensive work with primates to illustrate the evolutionary origins of morality. In this sense, for humans as well as for the great apes, morality is not a veneer masking self-interest and selfishness. It is intrinsic to our embodied evolutionary natures that the evolutionary outcome of empathy and altruism is conducive to species survival, and thus to understand that human nature is not only amoral, selfish and savage, but in this sense, humans are moral by nature. On this view not just sympathy and empathy, but also right and wrong are - to a certain extent - feelings that we share with other animals: even our feelings for ethics and justice are also part of nature. On this truly complete embodied view, goodness, generosity and genuine kindness come just as naturally to us as meaner, selfish and aggressive feelings.

De Waal then argues for starting our discussing about the evolution of morality with the reality of the presence of moral sentiments and intuitions, which not only is where we find the greatest continuity with other primates, but which also reflect the reality of our background as social animals (De Waal 2013:17). It is in this sense that biology helps us to understand why morality looks the way it does (De Waal 2013:19), and why the definite signs of community concern in the animal world are a clear indication that the building blocks of morality are older than humanity. Against this background, De Waal also argues that even philosophers who do not invoke God but argue that we reason ourselves towards moral truths, are still proposing a top-down process in which we first formulate the principles for moral behaviour and then impose them in human conduct and nature. It is equally reasonable, I believe, to ask whether moral deliberations should indeed take place on such an elevated plane: do not they need to be anchored in who and what we are?

For Frans de Waal, it is clear that the view of morality as a set of immutable principles, or laws that are ours to discover, ultimately comes from religion. It also does not really matter whether it is God, or human reason, or science, which formulates these laws. In fact, all of these approaches share a top-down orientation, and their chief premise is that humans do not know how to behave and that someone therefore must tell them (De Waal 2013:13). De Waal then asks the correct question: what if morality is created in day-to-day social interaction, and not on some abstract mental level? What if morality is actually grounded in the emotions, and this in the way we negotiate the world? This fact will then turn out to be at the heart of De Waal's argument for a bottom-up view of the origins of morality (De Waal 2013:23). ${ }^{2}$ In The Descent of Man, Darwin already clearly and unambiguously aligns morality with the evolutionary process and recognises emotional continuity with other animals, and in doing so recognised their capacity for sympathy or empathy. In language that is reminiscent of that of Maxine SheetsJohnstone, De Waal directly links emotional contagion and empathy: empathy connects bodies with bodies (De Waal 2013:131). In neuroscience language, we activate neural representations of motor actions in our own brain similar to the ones we perceive or expect in the other. Earlier empathy was seen as a cognitive skill, but now we know that the process is both simpler and more automatic. Empathy stems from unconscious bodily connections involving faces, voices and emotions. Humans do not decide to be empathetic, they just are (De Waal 2013:132). ${ }^{3}$ Neuroscience offers us two basic messages about empathy: the first is that there is no sharp dividing line between human and animal emotions; the second is that empathy runs from body to body. And at the heart of empathy lies emotional contagion (De Waal 2013:144).

We therefore come from a long line of ancestors with welldeveloped hierarchies for whom social inhibition was second nature. This still clearly shows in how much we invest moral rules with authority: sometimes, the authority is personal, like a super alpha male, or when we claim that God handed us the rules on a mountain top (De Waal 2013:154). At other times, we fall for the authority of reasoning, claiming that certain rules are so logically compelling that it would be silly to disobey them. Thus, humanity's reverence for the moral law betrays the mindset of a species that likes to stay in good terms with those who are in authority (De Waal 2013:154). In sum then, two great reinforcers support the social code by which primates and children live: the first is empathy and a desire for good relations leading to an avoidance of unnecessary distress; the second is the threat of physical consequences (reference and quote back to Boehm here). Over time these two reinforcers create an internalised set of guidelines, which De Waal calls one-on-one morality (De Waal 2013:160). This kind of morality permits partners of disparate abilities and strength to get along, such as males with females and adults with juveniles, binding them together in a mutually agreeable modus vivendi.

2.For those who believe that morality comes straight from God the creator, acceptance of evolution would open a moral abyss ... Why not assume that our humanity, including the self-control needed for a livable society, is built into us? (De Waa 2010:1; cf. De Waal 2013:2).

3.In an interesting and telling paragraph in which de Waal (2013) directly links emotiona contagion and empathy to the neurological role of mirror neurons, he argues that contagion and che opera creates the same intuitive and immediate connection through the human voice: Since birth (and even before) we know the human voice as the vehicle of pleasure, pain, rage, and so on. The voice plugs directly into our central nervous system. It reaches inside us as no artificial instrument ever will. We do not just infe the suffering of the soprano; we actually feel it and get goose bumps from it. As an opera lover, I feel emotionally drained by the end of every great performance. (p. 134) 
The idea of a 'top down' morality that can be argued from some 'first principles' De Waal indeed sees as a creationist myth (De Waal 2013:170). Also, Philip Kithcer has argued in his The Ethical Project that we often wrongly assume that there must be some authority in ethics, some point of view from which truth can be reliably discerned. The question, however, is why? Ethics may simply be something we work out together (cf. Kitcher 2011:207). De Waal thus presents us with a bottomup account of morality that assumes two basic levels of morality, one regarding social relationships and a broader one regarding the community: the first level is what he has called one-on-one morality, which reflects an understanding of how one's behaviour affects others; we share this level with all other social animals, and which develop similar inhibitions and codes of conduct. The second level is that of the community, or community concern. From an evolutionary perspective, it represents a radical step up in that the goal is harmony within the larger community. This is the level at which human morality begins to depart from anything else encountered so far, even though some animals show rudimentary forms of community concern (De Waal 2013:172).

If there is such a thing as the moral law, it is therefore unlikely to be identical everywhere. Our species certainly does possess invariant characteristics, and there is some degree of universality as we are preoccupied with helping and not hurting others. So, there are indeed huge differences in morality between societies and also changes within every society (De Waal 2013). Rather than reflecting an immutable human nature, morals are closely tied to the way we organise ourselves and negotiate our worlds (De Waal 2013:180). Therefore, someone like Philip Kitcher wants to argue for an alternative position that grounds morality in biology without actually denying that its specifics are decided by people. De Waal (2013) follows up on this and in the end can state:

I don't believe that watching chimpanzees or bonobos can tell us what is right or wrong, nor do I think that science can do so, but surely knowledge of the natural world helps us to understand how and why we came to care about each other and seek moral outcomes. (p. 185)

For this reason, moral laws are mere approximations, perhaps metaphors, of how we should behave.

So, the belief that morality somehow escapes a humble evolutionary origin has been drilled into us by religion and embraced by philosophy (De Waal 2013:227). It is directly at odds, however, with what science tells us about the primacy of intuitions and emotions. It is also at odds with what we know about other animals (De Waal 2013:227). This again underlines the plausibility of a bottom-up morality: the moral law is not imposed from above or derived from wellreasoned principles. On the contrary, it arises from ingrained values that have been there since the beginning of time (De Waal 2013:228). For De Waal, it is clear that the most fundamental of these ingrained values are derived from the survival value of group life. The desire to belong, to get along, to love and be loved, prompts us to do everything in our power to stay on good terms with those on whom we depend.

Finally, then, on the level of human morality, we leave the other primates behind. We care intensely about the group level and develop notions of right and wrong for everyone around, not just for ourselves and our close relations. This requires greater cognitive powers of abstractions as well as the anticipation of what may happen if we may let others get away with behaviour that does not even directly affect us. In this way, morality serves to spread the benefits of group life. And it is precisely a bottom-up naturalised ethics that offers an account of how we got to where we are. Finally, it is interesting to note that in an evolutionary sense, morality arose first, with religion then later latching on to it (De Waal 2013:239):

\section{From moral awareness to morality}

Two crucial, distinct questions that I finally want to deal with in this article can now be phrased as follows: taking into account the deep history of the evolution of hominids or hominines and humans, does the theory of (human) evolution help us to answer the following two questions: first, can we be morally good?, and, two, why should we be morally good? These questions are greatly enhanced if we return briefly to the issue of the evolution of morality, and ultimately ask why for theologians Jesus' person and work may contain a moral imperative for Christians today. In his provocative recent book, The Evolution of Morality (2006), Richard Joyce directly deals with the important question: if we human beings are the product of biological evolution, what exactly does that imply about our moral sense? The argument in the book develops along two distinct stages: in the first, Joyce asks the question: 'is the human capacity to make moral judgements the result of biological evolution?', and his conclusion is, yes, the moral sense is indeed an innate, evolved faculty (cf. Joyce 2006:142). This innate 'human moral sense', however, does not imply belief in any particular set of moral judgements or codes, but is, rather, a capacity to make moral judgements as such, a natural tendency to think about things in moral terms - an argument, as we saw, also made by scientists Frans De Waal and Maxine Sheets-Johnstone. This does not necessarily place Joyce at odds with Frans De Waal's notion that evolution has provided us with the psychological makeup, tendencies and the abilities to develop a compass for life's choices that includes our communities, because pro-social emotions are the 'essence of human morality'. Joyce is indeed correct, I believe, to find the 'essence of human morality' in discernment, prohibitions and evaluative judgements, that is, on the human capacity to think in moral, normative terms, not just some notion of empathy or trans-kin concern. While Joyce does see a substantial gap between the moral sense and the making of moral judgements, Frans De Waal has convincingly argued for identifying proto-morality precisely in pro-social behaviour and seeing those as 'building blocks' towards human morality. In this sense, the difference between De Waal and Joyce on the role on pro-social, proto-moral behaviour in animals is one of nuance and degree, with De 
Waal, as with Boehm, providing a more detailed biological substratum for Joyce's philosophical argument.

Clear moral judgements, however, have 'practical clout' in terms of the formal, social, conventional ways we come to make moral judgements and decisions, and as such they make inescapable and authoritative demands on us (cf. Joyce 2006:57-64). However, in an interesting convergence with evolutionary epistemology, whatever authoritative demand or practical clout moral judgements, codes, or laws, may have on us, it does not find its source in external or eternal or internal or evolutionary sanctions, but finds it in ongoing human discernment and convention. I will not follow Joyce to the end of his 'moral scepticism' and his conviction that no moral judgements are ever epistemically justified. On the contrary, exactly the fact that through discernment and moral judgements, pragmatically embedded in concrete cultural contexts we come to agreed-upon moral codes and the $a$ posteriori affirmation of our seasoned 'moral laws', provides the pragmatic 'clout' and postfoundationalist justification for our moral convictions.

I believe Joyce's very helpful distinctions between an innate, evolutionary moral awareness and the evaluative discernment needed for making intelligent moral judgements, does not have to lead to moral scepticism. On the contrary, each and every one of our beliefs does indeed have a complex causal history, but it would be absurd to conclude from evolutionary, neurological capacities, and from historical, philosophical or broader cultural reasons behind the history of our beliefs and belief-systems, that all our beliefs are unjustified, also including our religious and moral convictions. On a postfoundationalist view, some or our moral and religious beliefs are more plausible and more credible than others. This goes for our tendency to moralise and for the strong moral convictions we often hold: on a postfoundationalist view, we not only get to argue for some of the enduring moral codes and laws within the context of the Christian faith, but also for why it may be plausible to think that at least some of those moral beliefs are more reasonable than others. We have now seen that for Sheets-Johnstone, Boehm, De Waal and Joyce in spite of a powerful focus on the evolutionary origins of moral awareness, ethics as such emerge on a culturally autonomous level, which means that the epistemic standing of the particular moral judgements we make is independent of whatever the natural sciences can tell us about their origin and genesis. The evolutionary origins of the human moral sense indeed tell us nothing about how we get to construct moral decisions, codes and laws. That, however, does not mean that we cannot give a philosophical, postfoundationlist account of how we arrive at these informed judgements, codes and laws, without having to fall back on supranaturalist or sociobiological 'rules' for moral behaviour.

\section{Conclusion}

Exactly the fact that through discernment and moral judgement, pragmatically embedded in concrete cultural contexts, we come to agreed-upon moral codes and the $a$ posteriori affirmation of our seasoned 'moral laws', provides the pragmatic 'clout' and postfoundationalist justification for our moral convictions. The interdisciplinary conversation with and Maxine Sheets-Johnstone, Christopher Boehm, Frans De Waal and Richard Joyce on the natural history of morality, on evolutionary ethics and on our conceptions of good and evil, now yields the following tentative conclusions for me:

1. Evolution by natural selection can explain our tendency to think in normative terms, that is, our innate sense of moral awareness. However, evolutionary explanations of this moral awareness cannot explain our moral judgements, nor justify the truth claims of any of our moral judgements. Why and how we make moral judgements can only be explained on the level of the more interactive cultural evolution that is part of niche construction, and by taking into account the historical embeddedness of our moral codes in religious and political conventions. This argument, I believe, helps us to avoid committing the so-called genetic fallacy, that is, the mistake of thinking that tracing a belief's evolutionary origins automatically undermines its epistemic warrant. Or, put differently, the mistake of thinking that the evolutionary origins of our moral awareness necessarily explain away, and make impossible, the possibility to hold onto moral truth.

2. The important distinction between an innate, evolutionary moral awareness and the evaluative discernment needed for making intelligent moral judgement does not have to lead to moral scepticism or relativism. On the contrary, each and every one of our beliefs does indeed have a complex causal history, but it would be impossible to conclude from evolutionary, neurological capacities, and from historical, philosophical or broader cultural reasons behind the history of our beliefs and belief-systems, that all our beliefs are unjustified, including also our religious and moral convictions. On a postfoundationalist view, some of our religious beliefs are indeed more plausible and credible than others. This also goes for our tendency to moralise and for the strong moral convictions, we often hold: on this view, we not only get to argue for some of the enduring moral codes and laws within the context of the Christian faith, but also for why it may be plausible to think that at least some of those moral beliefs are more reasonable than others.

3. We have now seen that, in spite of a powerful focus on the evolutionary origins of moral awareness, ethics emerge on a culturally autonomous level, which means that the epistemic standing of the particular moral judgements we make is independent of whatever the natural sciences can tell us about their genesis. The evolutionary origin of the human moral sense indeed tells us nothing about how we get to construct moral decisions, codes and laws. That, however, does not mean that we cannot give a philosophical account of how we arrive at these informed judgements, codes and laws, without having to fall back on supranaturalist or sociobiological 'rules' for moral behaviour.

4. So, if we take into account what we have learned about so-called a priori accounts of knowledge or morality, 
our moral codes or 'laws' in the fullest and deepest sense of the word are indeed in an evolutionary epistemological sense of the word, a posteriori: for Christian theology, the choice will not be between a moral vision that is inherent in revelation and is therefore 'received' and not invented or constructed. Instead, on a postfoundationalist view, our moral codes and ethical convictions of what is 'received' is in itself an interpretative enterprise, shaped experientially through our embeddedness in communities and cultures. Through our intellectual and language abilities, we have created cultures, vast bodies of knowledge and moral codes, which in a broader sense can all be seen as cultural evolutionary artefacts that enable us to benefit from the trials and errors of the moral instincts of our ancestors. Evolutionary ethics helps us understand now such moral codes have developed, even if this does not yet lead to an evolutionary explanation for the formulation of specific moral codes, laws or norms. In this sense, then, there is a clear difference between an evolutionarily developed moral sense and the actual making of moral judgements.

5. However, moral judgements, and eventually moral codes and laws, have what Richard Joyce called 'practical clout' in terms of the formal, social and conventional ways we come to make moral judgements and decisions, and as such they make inescapable and authoritative demands on us. Moral codes are the core components of religions, also of the Christian faith, and in an evolutionary sense, religions can indeed be seen as part of the cultural, social structures that underpin our morality (cf. Broom 2003:164ff.).

\section{Acknowledgements Competing interests}

The author declares that he has no financial or personal relationships which may have inappropriately influenced him in writing this article.

\section{References}

Boehm, C., 2012, Moral origins. The evolution of virtue, altruism and shame, Basic Books, New York, NY.

Broom, D.M., 2003, The evolution of morality and religion, Cambridge University Press, Cambridge.

De Waal, F., 2006, Primates and philosophers: How morality evolved, Princeton University Press, Princeton, NJ.

De Waal, F., 2010, 'Morals without God?', New York Times, 17 October 2010, 1-3.

De Waal, F., 2013, The Bonobo and the Atheist, W.W. Norton \& Company, New York.

Joyce, R., 2006, The evolution of morality, MIT Press, Cambridge, MA.

Kitcher, P., 2011, The ethical project, Harvard University Press, Cambridge Massachusetts.

Kirkpatrick, L.A., 2005, Attachment, evolution, and the psychology of religion, The Guilford Press, New York.

Krebs, D. L. \& Denton, K.K., 2013, 'How did morality originate?', Evolutionary Psychology 11(1), 9-17.

Mithen, S., 1996, The prehistory of the mind: A search for the origins of art, religion, and science, Thames and Hudson, London.

Mithen, S., 2009, The singing Neanderthals: The origins of music, language, mind and body, Hatchett, London.

Ricoeur, P., 1992, Oneself as another, University of Chicago Press, Chicago, IL.

Ricoeur, P. \& Homans, P., 2008, 'Afterword: Conversations on Freud, memory, and loss', in W.B. Parsons, D. Jonte-Pace \& S.E. Henking (eds.), Mourning religion, p. 229, University of Virginia Press, Charlottesville, VA

Scruton, R., 2012, The face of God. The Gifford Lectures, Continuum, New York.

Sheets-Johnstone, M., 1990, The roots of thinking, Temple University Press, Philadelphia, PA.

Sheets-Johnstone, M., 1994, The roots of power, Open Court, Chicago, IL.

Sheets-Johnstone, M., 2008, The roots of morality, The Pennsylvania State Press, University Park, PA.

Singer, P., 2006, 'Morality, reason and the rights of animals', in S. Macedo \& J. Ober (eds.), Primates and Philosophers. How morality evolved, pp. 141-160, Princeton University Press (PUC), Princeton, NJ.

Stern, D., 1985, The interpersonal world of the infant: A view from psychoanalysis and developmental psychology, Basic Books, New York.

Van Huyssteen, J.W., 2006, Alone in the world? Human uniqueness in science and theology, Wm. B. Eerdmans, Grand Rapids, MI.

Van Huyssteen, J.W., 2011a, 'What makes us human? The interdisciplinary challenge to theological anthropology and Christology', Toronto Journal of Theology 26(2) 143-160.

Van Huyssteen, J.W., 2011b, 'From empathy to embodied faith? Interdisciplinary perspectives on the evolution of religion', in F. Watts \& L. Turner (eds.), Evolution, Religion and Cognitive Science: Critical and Constructive Essays, pp. 132-151CUP, Rambridge.

Wade, N., 2007, 'Scientist finds the beginnings of morality in primate behaviour', New York Times 20 Marth 2007, 1-3.

Wuketits, F.M., 1990, Evolutionary epistemology and its implications for humankind, SUNY Press, Albany, NY 